Araştırma Makalesi / Research Article

\title{
Kalkon ve Hidroksil Yan Grupları İçeren Yeni Metakrilat Polimerinin Sentezi, Karakterizasyonu, Termal ve Elektriksel Davranışları
}

\author{
Fatih BIRYAN \\ Fırat Üniversitesi, Fen Fakültesi, Kimya Bölümü, Elazığ/Türkiye \\ e-posta: fbiryan@firat.edu.tr ORCIDID: https://orcid.org/0000-0001-9198-3329
}

Geliş Tarihi: 26.03.2019; Kabul Tarihi: 19.09.2019

Dielektrik Özellik;

Termal Kararlılık;

Dielektrik Sabiti;

Aktivasyon enerjisi;

Kompozit
Anahtar kelimeler

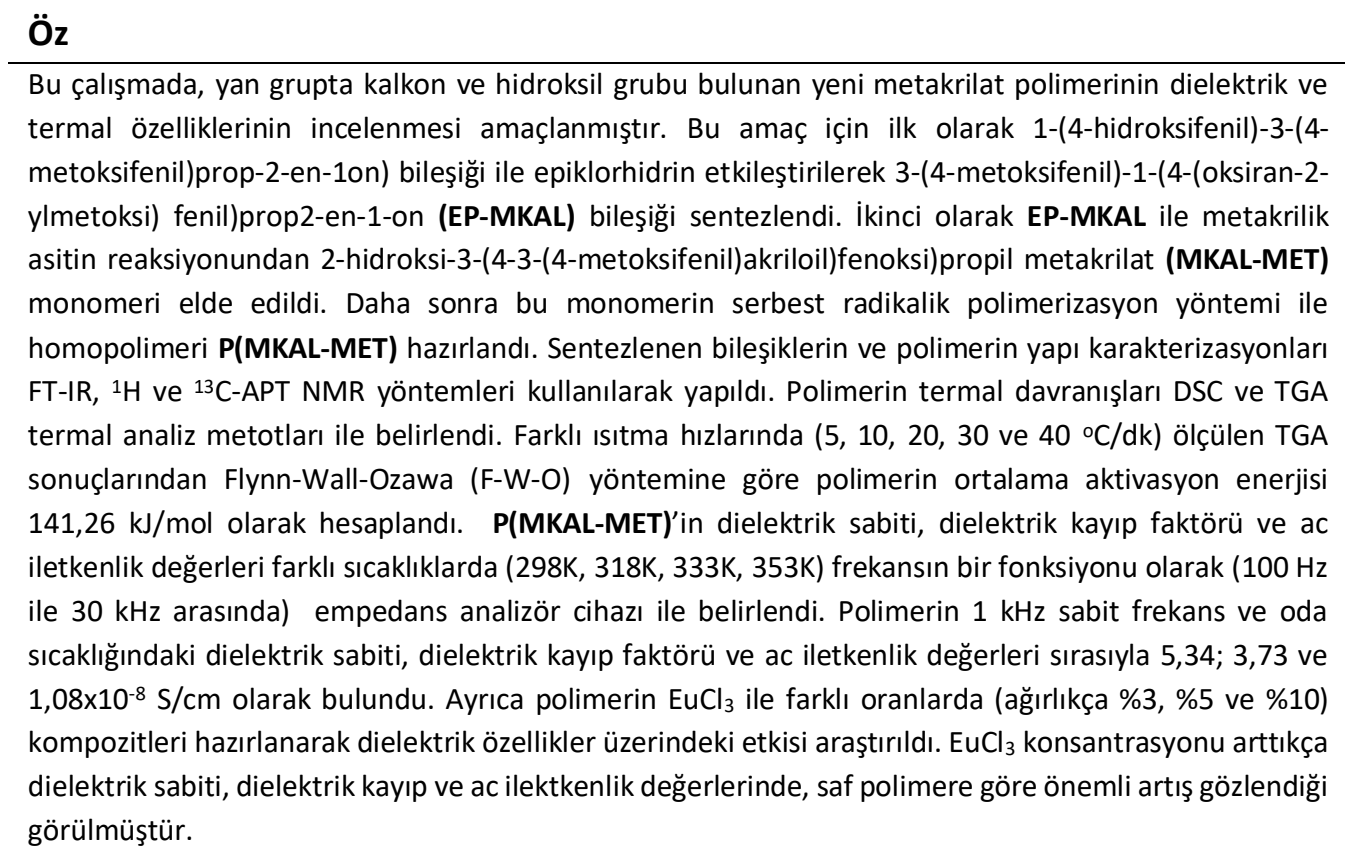

\section{Synthesis, Characterization, Thermal and Electrical Behaviors of A New Methacrylate Polymer Bearing Chalcone and Hydroxyl Side Groups}


and $30 \mathrm{kHz}$ ) as a function of frequency against increasing temperature (298K, 318K, 333K, 353K). Dielectric constant, dielectric loss and ac conductivity of P(MKAL-MET) were determined 5.34, 3.73 and $1.08 \times 10^{-8} \mathrm{~S} / \mathrm{cm}$, respectively at room temperature and $1 \mathrm{kHz}$. In addition, $3 \%, 5 \%$ and $10 \%$ by weight $\mathrm{EuCl}_{3}$ composites were prepared, and their effects on dielectric properties were investigated. The increasing $\mathrm{EuCl}_{3}$ concentration, dielectric properties were significantly increased compared to pure polymer.

(C) Afyon Kocatepe Üniversitesi

\section{Giriş}

Gelişen yeni polimer sentez yöntemleri sayesinde polimerlere her geçen gün yenileri ilave edilmektedir. Polimerik malzemeler günlük hayatımızın hemen her alanında rastlanmanın yanı sıra yaşamımızın vazgeçilmez parçaları olmuşlardır. Polimerik malzemelerin yapısal özelliklerinin istenildiği gibi ayarlanabilir olması ve ekonomik olarak elde edilebilmesi bu kadar geniş kullanım alanlarına sahip olmalarını sağlamaktadır (Bezgin 2011).

Fonksiyonel polimerler makromoleküler kimyasının gelişmesinden sonra ticari ve bilimsel olarak ilgi çekici olmuştur. Fonksiyonel polimerler, istenilen fonksiyonel zincirlere sahip ya da kimyasal modifikasyonla elde edilmiş monomerlerin polimerizasyon veya kopolimerizasyonu ile hazırlanır. Polimer zincirinde bulunan yan gruplar termal bozunma sırasında ayrışmanın nasıl gerçekleştiğini anlamada oldukça önemlidir. Bu kapsamda poli(metakrilik esterler) ve yan zincirde farklı grupların bulunduğu polimerlerin termal bozunma davranışlarına dikkat çekmek gerekir. Bazı polimetakrilatlar ısınmanın etkisiyle nispeten kolayca monomerlerine parçalanırlar. Buna karşılık bazı polimerlerde ise depolimerizasyon olmaksızın ester ayrışması gerçekleşir. Bazı metakrilat polimerlerin ise termal bozunması ana zincirde kırılmalar şeklinde gerçekleşir ve buna depolimerizasyon denir. Bozunma yüksek sıcaklıklarda ester ayrışmasıyla devam eder, sıcaklık yükseldikçe küçük moleküllerin eliminasyonu ve halkalı anhidrit yapısı oluşur (Coşkun ve ark. 2003 ). Hidroksi akrilat ve metakrilatlar biyolojik uygulamalar için kullanılan fonksiyonel polimerler arasında hidrofilik olmalarından ve suda çözünürlüklerinden dolayı ilgi çekmektedirler (Popescu ve ark. 2010). Bu polimerler kontak lensler, diş malzemeleri, optik lensler, hidrojeller gibi kontrollü ilaç salınımı için kullanılan biyomedikal ürünlerde ve ilaçlarda kullanılmaktır (Maitz 2015). Hidroksil fonksiyonlu monomerler çok çeşitlilik gösterir. Hidroksil yan grupları içerdiklerinden dolayı çapraz bağlanma için ideal monomerlerdir. Daha ileri $\mathrm{ki}$ aşamalarda polimerin kimyasal modifikasyonu ile yeni monomerik yapılı bloklar elde edilebilir. Ayrıca hidroksil fonksiyonlu monomerler farklı uygulamalar için kopolimerde hidrofobik/hidrofilik dengesini sağlamak için de kullanılabilirler (Biryan 2013).

Hidroksil fonksiyonlu metakrilatların kimyasal sentezi etilen oksit ve propilen oksit gibi farklı halkalı eterler ile akrilik ve metakrilik asitin reaksiyonuna dayanır. Siklik oksitlere ulaşılamadığında veya yeterince reaktif olmadığında, hidroksil fonksiyonlu monomer sentezlemek için diğer prosedürleri kullanmak gerekir (Perez ve ark. 2000).

Dielektrikler, esasen bir dış elektrik alan etkisi altında hareket edebilen serbest taşıyıcı bulundurmadıklarından dolayı yalıtkandırlar ve çok düşük iletkenlikleri sebebiyle geniş bir malzeme grubuna sahiptirler (Tareev 1975, Neamen 1997). Dielektrik malzemeler birçok yalıtım malzemelerinden kondansatörlere kadar çeşitli kullanım alanlarına sahiptirler. Dielektrik malzemeler, bir dış elektrik alana maruz kaldığı durumda yük veya enerji depolayabilme yeteneği gösterirler (Symth 1955, Biryan ve Demirelli 2017). Literatürde metakrilat polimerlerinin dielektrik özellikleri hakkında çalışmalar mevcuttur. Ancak kalkon ve hidroksil yan grubunu birlikte ihtiva eden metakrilat polimerinin sentezine, termal ve dielektrik özelliklerine rastlanmamıştır. Literatürdeki bu boşluğu doldurmak amacıyla yeni metakrilat polimeri hazırlanmıştır. Sentezlenen bu yeni polimerin yan zincirinde hem hidroksil grubunun hem de konjugasyona sahip kalkon 
grubunun varlığı ile polimerin termal ve dielektrik özelliklerinin incelenmesi, bu alanda yapılacak çalışmaları önemli kılmıştır. Bu polimerin dışarıdan uygulanan bir elektrik alan altında polarlanabilecek kapasiteye sahip konjuge kalkon ve hidroksil grubunun dielektrik özelliklere etkisinin incelenmesi amaçlanmıştır. Ayrıca hazırlanan bu homopolimere farklı oranlarda $\mathrm{EuCl}_{3}$ katkılanarak elde edilen kompozitlerin dielektrik özelliklerindeki değişimin incelenmesi amaçlanmıştır.

\section{Materyal ve Metot}

Sentez basamaklarında kullanılan 4hidroksiasetofenon, 4-metoksi benzaldehit, epiklorhidrin, metakrilik asit, sodyum hidroksit, piridin, 2,2' azobisizobütironitril (AIBN), Europium (III) klorür, etil alkol, asetonitril ve tetrahidrofuran Sigma-Aldrich, NMR çalışmalarında döteryumlu çözücü olarak kullanılan $\mathrm{CDCl}_{3}, \mathrm{DMSO}^{-\mathrm{d}_{6}}$ ve $\mathrm{EuCl}_{3}$, Merck firmasından temin edilmiştir.

Bileşiklerin karakterizasyonunda ve fiziksel ölçümlerinde; FT-IR spektrumları Perkin Elmer Spectrum One FT-IR spektrometre cihazı ile, NMR Spektrumları Bruker Avance III-400, DSC ve TGA analizleri SHIMADZU marka DSC-50 ve TGA-50 termal analiz cihazları ve dielektrik parametrelerin ölçümlerinde Quadtech 7600 Precision LCR meter cihazı kullanılmıştır.

\subsection{Sentez Prosedürleri}

2.1.1. 1-(4-Hidroksifenil)-3-(4-metoksifenil)prop-2en-1on) Bileşiğinin (OH-MKAL) Sentezi

Metoksi sübstitüe hidroksikalkon bileşiği ClaisenSchmidt kondenzasyon protokolüne göre sentezlendi (Funiss ve ark. 2004, Modzelewska ve ark. 2006).

3,00 g (22,02 mmol) 4'-hidroksiasetofenon $50 \mathrm{~mL}$ mutlak etil alkolde çözüldü ve 250 mL'lik reaksiyon balonuna ilave edildi. Reaksiyon ortamı $0{ }^{\circ} C^{\prime}$ ye getirildi daha sonra \%30'luk $\mathrm{KOH}$ çözeltisi reaksiyon ortamına ilave edildi. Yarım saat karıştıııldıktan sonra $22,02 \mathrm{mmol}$ sübstitüe aldehit damla damla ilave edildi. Reaksiyona oda sıcaklığında 24 saat devam edildi. Daha sonra madde sodyumbisülfitli suda çöktürüldü. Bol suyla yıkanıp etüvde kurutuldu ve katı madde OH-MKAL elde edildi. P(MKAL-
MET)'ın sentez reaksiyonuna ait tüm basamaklar Şekil 1'de verilmiştir.

\subsubsection{3-(4-Metoksifenil)-1-(4-(oksiran-2-ylmetoksi Ifenil)prop2-en-1-on Bileşiğinin (EP-MKAL) Sentezi}

3-(4-metoksifenil)-1-(4-(oksiran-2-ylmetoksi)fenil) prop-2-en-1-on bileşiği literatürdeki metoda göre sentezlenmiştir (Podkoscıelna ve ark. 2006). Üç ağızlı $100 \mathrm{~mL}$ lik reaksiyon balonuna 3,00 g (11,80 mmol) EP-MKAL tartıldı ve $35 \mathrm{~mL}$ epiklorhidirinde çözüldü. Çözelti manyetik karıştırıcıda karıştırılırken üzerine $\mathrm{NaOH}^{\prime}$ in aşırısı $1,00 \mathrm{~g}$ ( $25 \mathrm{mmol}$ ) ilave edildi. Reaksiyon $110{ }^{\circ} \mathrm{C}$ sıcaklıkta geri soğutucu altında 5 saat daha sonra oda sıcaklığında 6 saat daha karıştırıldı. Reaksiyon sonlandıktan sonra ortamdaki tuz süzülerek uzaklaştırıldı ve dietileter ile yıkandı. Daha sonra dietileter ve epiklorhidrinin fazlası vakum altında döner buharlaştırıı ile uzaklaştırıldı. Geride kalan madde dietileter fazına alınarak saf su ile üç kez yıkandı. Organik fazdaki çözücü döner buharlaştırıcı ile uzaklaştırıldı. Ürün sarı renkli bir katı olarak elde edildi.

EP-MKAL; FT-IR $\left(\mathrm{KBr}, \mathrm{cm}^{-1}\right)$ : 912 vepoksi halkasI, 1255 ve $1168 v \mathrm{C}-\mathrm{O}, 1602,1573$ ve $1505 v \mathrm{C}=\mathrm{C}, 1657$ $v C=0,2932$ ve $2838 v C$-H(Alifatik), 3068 ve $3006 v C$ $\mathrm{H}$ (Aromatik). EP-MKAL'ın ${ }^{1} \mathrm{H} \quad \mathrm{NMR}(400 \mathrm{MHz})$ spektrumu Şekil 2'de gösterilmiştir, karakteristik pikler $\left(\mathrm{CDCl}_{3}\right.$-d) $\delta /$ ppm: 8,06 (2H, H6, dublet J:8), $7,82(1 \mathrm{H}, \mathrm{H} 4$, dublet J:12), 7,63 (2H, H3, dublet, J:8); $7,45(1 \mathrm{H}, \mathrm{H} 5$, dublet $\mathrm{J}: 16) ; 6,96(4 \mathrm{H}, \mathrm{H} 2$ ve $\mathrm{H} 7$, dublet J:8); 4,37 ve $4,35(2 \mathrm{H}, \mathrm{H} 8) ; 3,87(3 \mathrm{H}, \mathrm{H} 1) ; 3,40(1 \mathrm{H}$, H9); 2,95 ve $2,81(2 \mathrm{H}, \mathrm{H} 10)$. EP-MKAL'In ${ }^{13} \mathrm{C}$ NMR (400 MHz) spektrumu Şekil 3'te gösterilmiştir, karakteristik pikler $\left(\mathrm{CDCl}_{3}\right.$-d) $\delta / \mathrm{ppm}$ : $188,76 \mathrm{C} 8$; 162,05 C12; 161,55 C2; 131,78 C9; 130,74 C10; 130,19 C4; 127,72 C5; 119,39 C7; 114,36 C3 ve C11; 68,87 C13; 55,45 C1; 49,97 C14; 44,67 C15.

2.1.3. 2-Hidroksi-3-(4-3-(4-metoksifenil)akriloil) fenoksi)propil metakrilat Bileşiğinin (MKAL-MET) Sentezi

MKAL-MET monomeri literatürdeki prosedüre göre hazırlandı (Biryan 2013). Üç ağızlı 100 mL lik reaksiyon balonuna $0,91 \mathrm{~g}(10,63 \mathrm{mmol})$ metakrilik asit ve $1,00 \mathrm{~mL}$ piridin konulup Isıtıcılı manyetik karıştırıcı ile karıştırıldı. Sonra 3,00 g EP-MKAL (9,67 mmol) dioksan çözücüsünde çözerek bir damlatma hunisi yardımıyla reaksiyon balonundaki çözelti 
üzerine $30 \mathrm{dk}$ içinde damlatılarak ilave edildi. Monomerin polimerleşmesini engellemek için ortama durdurucu olarak hidrokinon ilave edilerek reakiyon sıcaklığı $80^{\circ} \mathrm{C}$ ye getirildi. Reaksiyon 18 saat devam ettirildi ve sonra ortamdaki çözücü vakum altında uzaklaştırıldı. Monomer diklorometan çözücüsüne alınarak seyreltik $\mathrm{NaHCO}_{3}$ çözeltisi ile üç kez yıkandı. Organik faza, susuz $\mathrm{MgSO}_{4}$ ilave edildi ve soğuk ortamda 24 saat bekletildi. Daha sonra $\mathrm{MgSO}_{4}$ süzüldü ve çözücü döner buharlaştırıcı ile uzaklaştırıldı. Ürün sarı renkli bir katı olarak elde edildi.

MKAL-MET; FT-IR $\left(\mathrm{NaCl}, \mathrm{cm}^{-1}\right): 1259$ ve 1168 vC-O, $1598 v C=C, 1653 v C=0,1718 v C=0$ (ester) 2928 ve 2868 vC-H(Alifatik), 3068 ve 3006 vC-H(Aromatik),
3440 vO-H. MKAL-MET'ın ${ }^{1} \mathrm{H}$ NMR (400 MHz) spektrumu Şekil 4'te gösterilmiştir, karakteristik pikler ( $\delta / p p m): 8,04(2 \mathrm{H}, \mathrm{H} 7$, dublet J:8); 7,78 (1H, $\mathrm{H9}$, dublet J:12); 7,61 (2H, H10, dublet J:8); 7,46 (1H, $\mathrm{H} 8$, dublet J:16); 7,02-6,96 (4H, H6 ve $\mathrm{H} 11$, dublet $\mathrm{J}: 8) ; 6,18$ ve $5,61(2 \mathrm{H}, \mathrm{H} 2$, singlet); 4,37 (2H, H3, dublet, J:8) ve 4,17 (1H, H4, multiplet); 3,97 (2H, H5, dublet, J:8); 3,87 (3H, H12, singlet); 3,00 (1H, H13); 1,98 (3H, H1, singlet). MKAL-MET'ın ${ }^{13} \mathrm{C}$ NMR (400 $\mathrm{MHz}$ ) spektrumu Şekil 5'te gösterilmiştir, karakteristik pikler $\left(\mathrm{CDCl}_{3}-\mathrm{d}\right) \delta / \mathrm{ppm}$ : 188,81 C11, 167,57 C4; 161,94 C8; 161,58 C17; 144,15 C13; 135,70 C3; 131,89 C19; 139,79-130,21 C10 ve C15; 127,71 C14; 126,56 C2; 119,36 C12; 114,40 C9 ve C16; 68,86 C7; 68,56 C6; 67,11 C5; 55,46 C18; 18,40 C1.

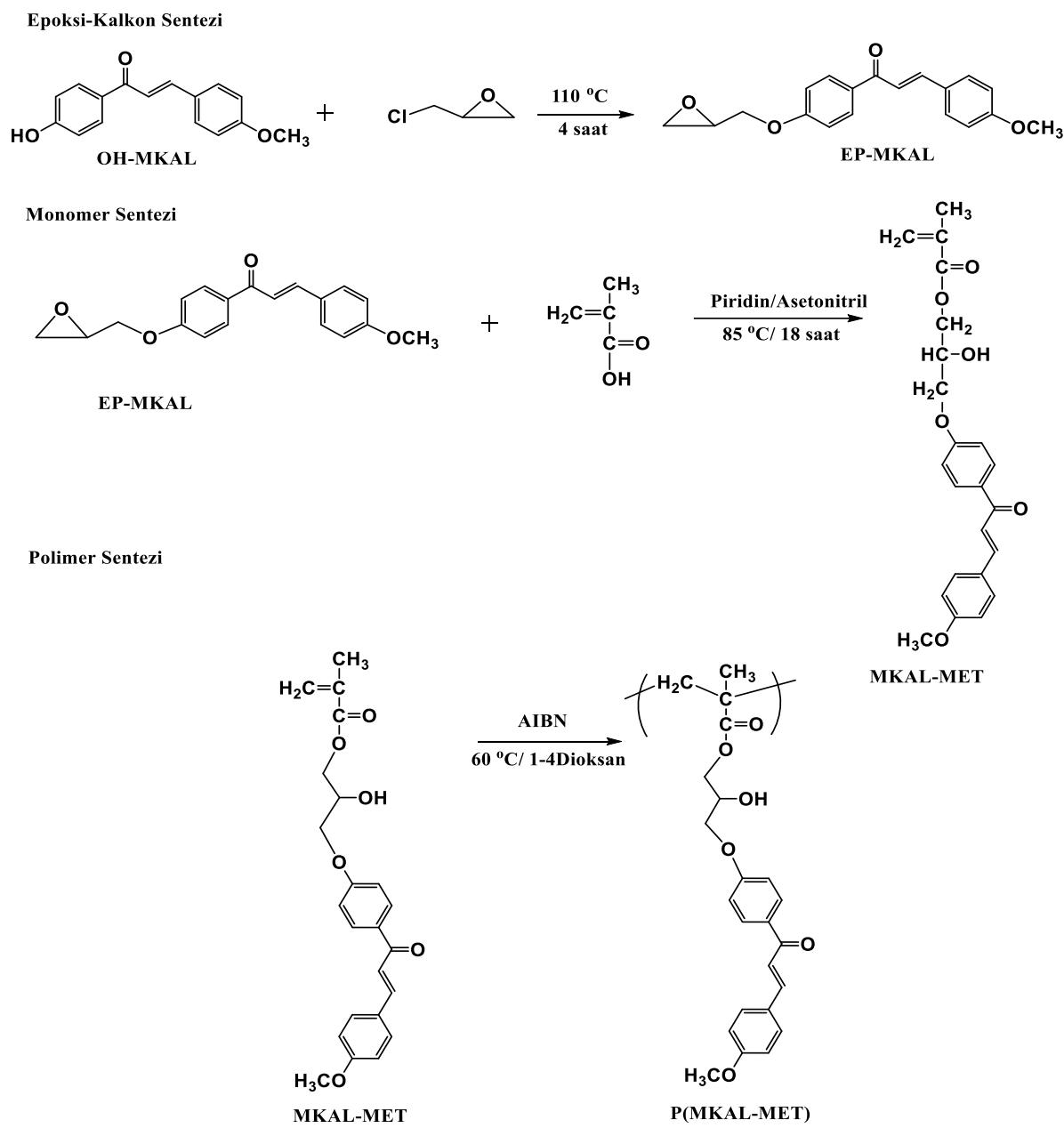

Şekil 1. Sentezlenen Yapıların Genel Sentez Şeması.

2.1.4.Poli(2hidroksi-3-(4-3-(4-metoksifenil) akriloil)fenoksi)propil metakrilat) P(MKAL-MET) Sentezi

Kauçuk kapaklı bir polimerizasyon tüpüne, 1,00 g MKAL-MET monomeri konuldu ve $2 \mathrm{~mL}$ dioksan ile çözüldü ve ardından başlatıcı olarak ağırlıkça \%1
$(0,01 \mathrm{~g})$ AIBN ilave edildi. Hazırlanan polimer tüpü argon gazından geçirildikten sonra $60{ }^{\circ} C^{\prime}$ ye ayarlı yağ banyosuna konuldu ve 8 saat bekletildi. Polimer n-hekzan içerisinde çöktürüldü. Çöktürme işlemi iki kez tekrarlandı. Çöktürülen polimer önce oda 
sıcaklığında sonra vakum altında $40{ }^{\circ} \mathrm{C}$ 'de 24 saat kurutuldu.

P(MKAL-MET); FT-IR (KBr, cm-1): 1259 ve 1168 vCO, $1598 v \mathrm{C}=\mathrm{C}, 1653 v \mathrm{C}=\mathrm{O}, 1728 v \mathrm{C}=\mathrm{O}$ (ester) 2941 ve $2865 v \mathrm{C}-\mathrm{H}$ (Alifatik), $3068 v \mathrm{C}-\mathrm{H}$ (Aromatik), 3424 vO-H. P(MKAL-MET)'in ${ }^{1} \mathrm{H} \quad \mathrm{NMR}^{\prime \prime}$ Şekil $6^{\prime}$ da gösterilmiştir. Karakteristik pikler; $\left(\mathrm{CDCl}_{3}-\mathrm{d}\right) \delta / \mathrm{ppm}$ : 8,10-6,96 (Kalkon grubuna ait protonlar 10H); 5,43 (-OH protonu $1 \mathrm{H}) ; 4,07-3,75$ (Alifatik yan grup protonları $5 \mathrm{H}$ ve $-\mathrm{CH}_{3}$ protonları $3 \mathrm{H}$ ); 1,67-0,43 (Ana zincir protonları $5 \mathrm{H}$ ). P(MKAL-MET)'ın ${ }^{13} \mathrm{C} N \mathrm{NMR}^{\prime}$ । Şekil 7'de verilmiştir. Karakteristik pikler; $\left(\mathrm{CDCl}_{3}\right.$-d) ठ/ppm: 187,64 (keton karbonili); 170,17 (ester karbonili), 162,75 ve 161,61 (oksijen atomuna bağlı ipso karbonları), 143,64 ve 119,79 (olefinik $-\mathrm{CH}$ karbonları), 131,08 ve 114,80 (aromatik $-\mathrm{CH}$ karbonları), 69,69-65,43 (alifatik yan grup karconları), 55,03 (metoksi karbonu), 18,12 (ana zincir karbonları).

\subsection{Polimerin Termal Özelliklerinin Belirlenmesi}

P(MKAL-MET) polimerinin camsı geçiş sıcaklığı DSC termogramından, termal bozunması da TGA ölçümlerinden belirlendi. Bu amaçla alınan belirli miktarlardaki polimer örneği azot gazı atmosferinde DSC de $20{ }^{\circ} \mathrm{C} / \mathrm{dk}$ ısıtma hızıyla TGA da ise $10^{\circ} \mathrm{C} / \mathrm{dk}$ ısıtma hızıyla sırasıyla $200{ }^{\circ} \mathrm{C}$ ve $600{ }^{\circ} \mathrm{C}^{\prime}$ ye kadar ısıtılarak DSC ve TGA eğrileri kaydedildi. Ayrıca kinetik veriler temelinde polimerlerin aktivasyon enerjilerini belirleyebilmek için Flynn-Wall-Ozawa (F-W-O) integral yöntemi kullanıldı. Bu yönteme göre Ea'yı belirlemek için farklı ısıtma hızlarında (10, $20,30,40{ }^{\circ} \mathrm{C} / \mathrm{dk}$ ) TGA sonuçları alınarak karşılaştırmalı olarak grafiğe geçirildi. Sonra dönüşüm değerleri kullanılarak aktivasyon enerjisi belirlendi. Farklı dönüşüm değerleri için $1 / T^{\prime}$ ye karşı $\log \beta$ değerlerinin grafiğe geçirilmesi sonucu aktivasyon enerjisi hesaplandı (Zoglio ve ark. 1968).

\subsection{P(MKAL-MET)-EUCl}

\section{hazırlanması}

Kompozitleri hazırlamak için 0,15 g P(MKAL-MET) ve ağırlıkça \%3, \%5 ve \%10 oranında $\mathrm{EuCl}_{3}$ hassas bir şekilde tartıldı ve THF içerisinde ultrasonik sonikatörde 3 saat homojenleştirildikten sonra bu karışımların çözücüsü uzaklaştırıldı. Elde edilen kompozitler vakumlu etüvde kurutuldu.

\subsection{Polimerin Dielektrik Özelliklerinin Belirlenmesi}

Polimerin dielektrik davranışlarını incelemek amacıyla öncelikle toz halindeki bileşikler 4 ton basınç altında disk yardımıyla tablet haline getirildi. Elde edilen tabletlerin kalınlığı dijital kumpas ile hassas bir şekilde ölçüldü. Daha sonra altın kondaktörler yardımıyla empedans analiz cihazına bağlanan numunelerin kapasitans değerleri (Cp), dielektrik kayıp faktörü (DF) ve Gp parametreleri ölçüldü. Ölçümler $100 \mathrm{~Hz}$ ile 30 kHz aralığında sabit sıcaklıklarda artan frekansa karşı yapıldı. Dielektrik parametreleri aşağıdaki formüller yardımıyla hesaplandı (Biryan ve ark. 2017, Coşkun ve Coşkun 2017, Koran ve ark. 2017).

$$
\begin{aligned}
& \varepsilon^{\prime}=C_{p} \frac{d}{A \varepsilon_{0}} \\
& \varepsilon^{\prime \prime}=\varepsilon^{\prime} D F \\
& \sigma=G_{p} \frac{d}{A}
\end{aligned}
$$

A: Numunenin alanı $\left(\mathrm{m}^{2}\right) ; \quad \varepsilon^{\prime}$ : Dielektrik sabiti C:Numunenin kapasitansı(F); $\quad \varepsilon^{\prime \prime}$ : Dielektrik kayıp d: Numunenin çapı (m) $\varepsilon_{0}$ : Boşluğun dielektrik sabiti $\left(8.85 \times 10^{-12} \mathrm{~F} / \mathrm{m}\right)$ Elde edilen bileşikler için frekansa karşı ölçülen dielektrik sabiti $\left(\varepsilon^{\prime}\right)$, dielektrik kayıp $\left(\varepsilon^{\prime \prime}\right)$ ve iletkenlik $\left(\log \sigma_{a c}\right)$ sonuçları aşağıda grafikler halinde de verilmiştir. Tablo $1^{\prime}$ de artan sıcaklıklarda ve sabit frekanstaki $(1000 \mathrm{~Hz})$ dielektrik sonuçları gösterilmiştir.

Çizelge 1. P(MKAL-MET)'ın Farklı Sıcaklıklarda 1 kHz'deki Dielektrik Sonuçları.

\begin{tabular}{ccccc}
\hline & K & $\varepsilon^{\prime}$ & $\varepsilon^{\prime \prime}$ & $\sigma_{\mathrm{ac}}(\mathrm{S} / \mathrm{cm})$ \\
\hline $\mathbf{2 9 8}$ & 5,34 & 3,73 & $1,08 \times 10^{-8}$ \\
$\mathbf{P}(\mathrm{MKAL}-\mathrm{MET})$ & $\mathbf{3 1 8}$ & 6,63 & 8,33 & $1,52 \times 10^{-8}$ \\
& $\mathbf{3 3 3}$ & 7,31 & 9,12 & $1,70 \times 10^{-8}$ \\
& $\mathbf{3 5 3}$ & 8,39 & 10,41 & $1,82 \times 10^{-8}$ \\
\hline$\varepsilon^{\prime}:$ Dielektrik Sabiti; $\varepsilon^{\prime \prime}$ : Dielektrik kayı; $\sigma_{a c}$ iletkenlik; K: Kelvin
\end{tabular}

\section{Bulgular}

Çalışmanın ilk aşamasında 4-hidroksiasetofenon ile sırasıyla 4-metoksibenzaldehit bileşiği ClaisenSchmidt kondenzasyon protokolüne göre reaksiyona sokularak hidroksi kalkon bileşiği $\mathbf{O H}-$ MKAL elde edildi (Funiss ve ark. 2004, Modzelewska ve ark. 2006). İinci olarak epiklorhidrin ile $\mathbf{O H}$ MKAL'ın reaksiyonundan EP-MKAL bileşiği elde edildi (Podkoscielna ve ark. 2006). Monomer sentez 
basamağının son aşamasında EP-MKAL ile metakrilik asitin piridin ve dioksan varlığında etkileştirilmesi ile kalkon sübstitüe hidroksil yan gruplu MKAL-MET bileşiği elde edildi. Daha sonra elde edilen bu monomerin serbest radikalik polimerizasyon yöntemi ile homopolimeri hazırlandı. Bileşiklerin genel sentez gösterimi Şekil 1' de verilmiştir. Monomer sentez aşamasındaki elde edilen bileşiklerin ve homopolimerin karakterizasyonları ayrıntılı bir şekilde materyal ve metot bölümünde verilmiştir.

EP-MKAL bileşiğinin FT-IR spektrumu incelendiğinde yapısında bulunan epoksit halkasına ait $\mathrm{C}-\mathrm{H}$ eğilme titreşiminin $\left(912 \mathrm{~cm}^{-1}\right)$ gözlenmesi, ${ }^{1} \mathrm{H}-\mathrm{NMR}$ spektrumundaki (Şekil 2) epoksit halkasına ait -CH protonlarının görülmesi ve bunun yanında integral yüksekliklerinin yapı ile uyumlu olması ve ${ }^{13} \mathrm{C}$-APTNMR'ın (Şekil 3) bu sonuçları desteklemesi ile bileşiğin oluştuğu tespit edildi. MKAL-MET bileşiğinin FT-IR spektrumunda ise epoksit halkasının açıldığı $912 \mathrm{~cm}^{-1}$ deki sinyalin kaybolması ve yeni bir sinyal olan $3440 \mathrm{~cm}^{-1}$ deki $-\mathrm{OH}$ sinyalinin oluşumu ile açıkça görülmektedir. Ayrıca $1718 \mathrm{~cm}^{-1}$ deki ester karbonili de yapıya ait karakteristik bir piktir. ${ }^{1} \mathrm{H}-\mathrm{NMR}$ spektrumunda (Şekil 4) metakrilatta bulunan metil protonlarının yanı sıra vinil protonlarının ve $-\mathrm{OH}$ protonun görülmesi, ayrıca buna ek olarak ${ }^{13} \mathrm{C}$-APT-NMR (Şekil 5) tekniği ile de primer, sekonder ve tersiyer karbonların kaç ppm'de gözlendiği ayrıntılı olarak tespit edilerek elde edilen sonuçların literatür ile de uyumlu olması yapıyı kanıtlamaktadır.

P(MKAL-MET)' In ${ }^{1} \mathrm{H}-\mathrm{NMR}$ spektrumunda (Şekil 6) vinil grubuna ait $-\mathrm{CH}$ protonlarının kaybolması ve ana zincir protonları olarak daha yüksek alana kayması, piklerin yayvan olarak gözlemlenmesi ve integral yüksekliklerinin proton sayıları ile eşleşmesi ve ${ }^{13}$ C-APT-NMR spektrumu (Şekil 7) da polimerin yapısını doğrulamaktadır.

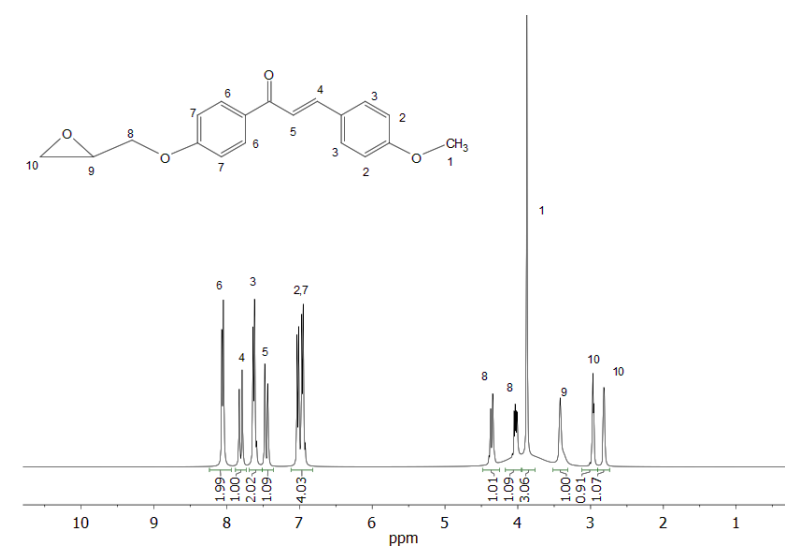

Şekil 2. EP-MKAL'nin ${ }^{1} \mathrm{H}-\mathrm{NMR}$ Spektrumu $\left(\mathrm{CDCl}_{3}-\mathrm{d}\right)$.

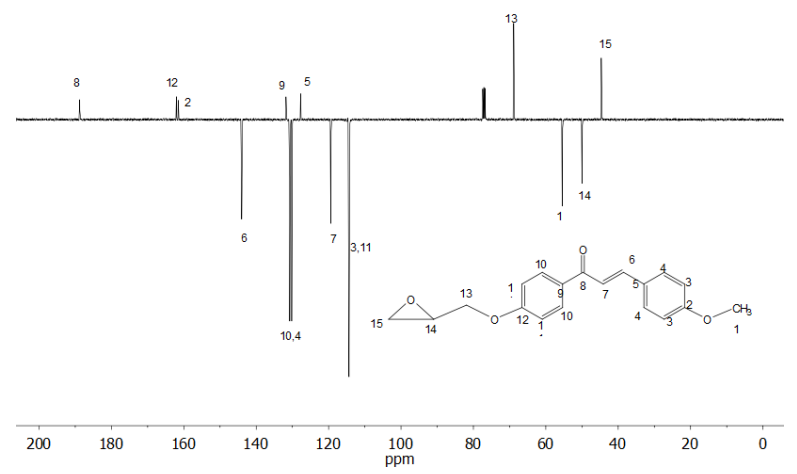

Şekil 3. EP-MKAL'nin ${ }^{13} \mathrm{C}-\mathrm{NMR}$ Spektrumu $\left(\mathrm{CDCl}_{3}-\mathrm{d}\right)$.

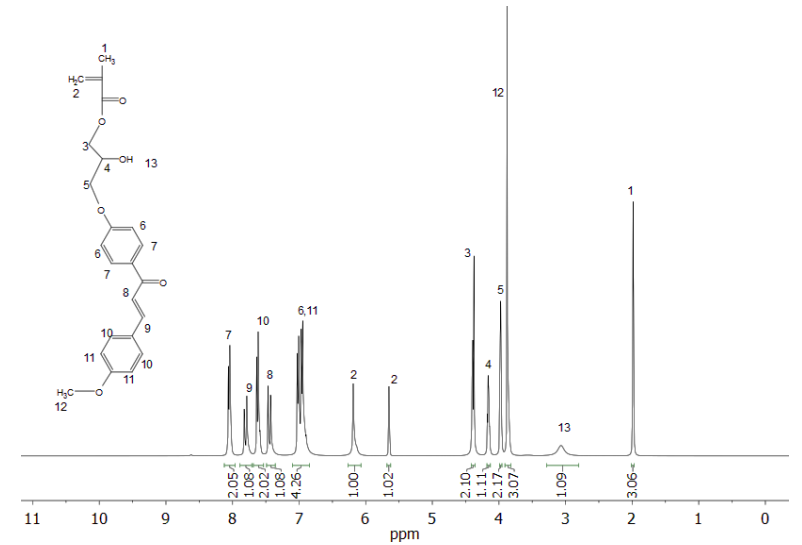

Şekil 4. MKAL-MET'in ${ }^{1} \mathrm{H}-\mathrm{NMR}$ Spektrumu $\left(\mathrm{CDCl}_{3}-\mathrm{d}\right)$.

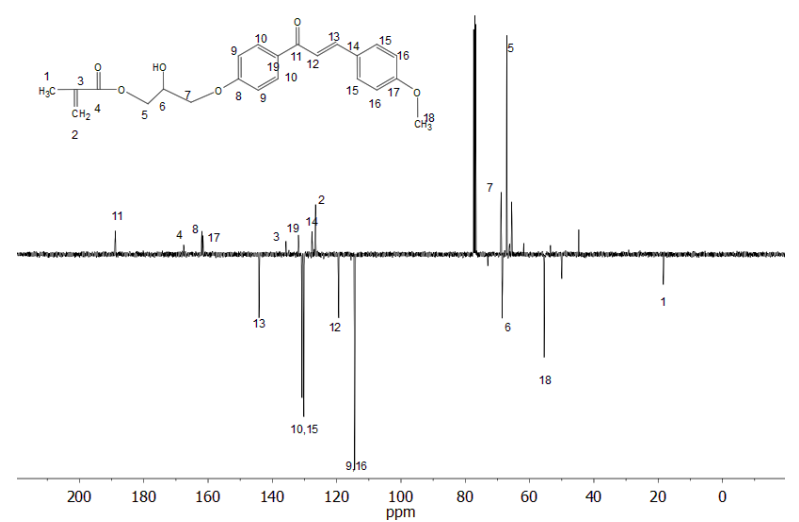

Şekil 5. MKAL-MET'in ${ }^{13} \mathrm{C}-\mathrm{NMR}(\mathrm{APT})$ Spektrumu $\left(\mathrm{CDCl}_{3^{-}}\right.$ d). 


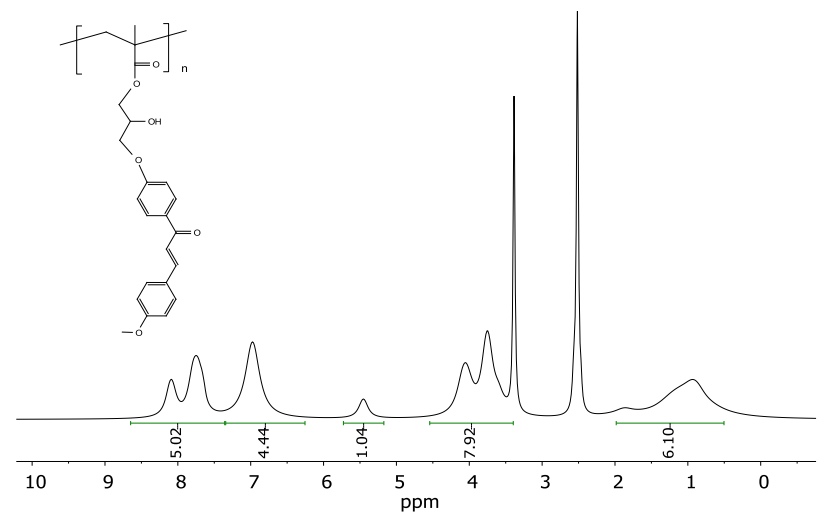

Şekil 6. P(MKAL-MET)' In ${ }^{1} \mathrm{H}-\mathrm{NMR}$ Spektrumu (DMSO).

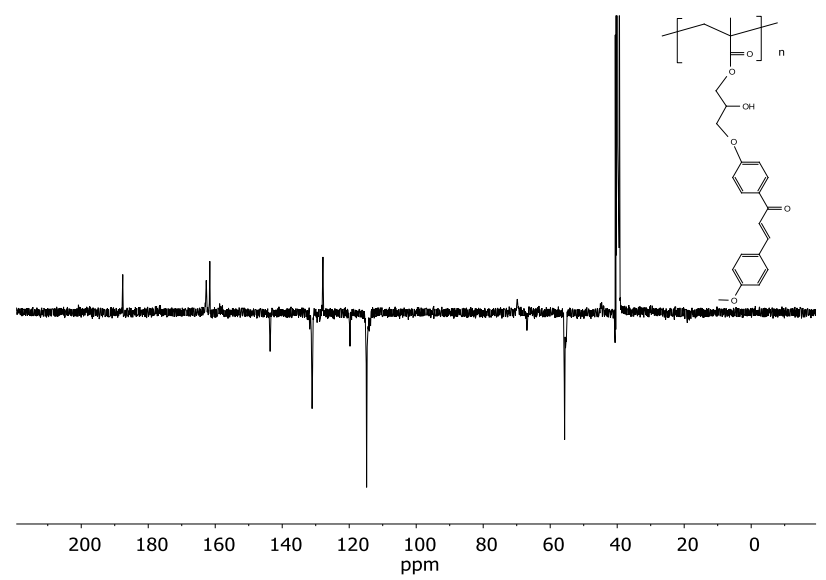

Şekil 7. P(MKAL-MET)'ın ${ }^{13}$ C-NMR Spektrumu (DMSO).

P(MKAL-MET)'ın DSC ve TGA eğrileri sırasıyla Şekil 8 ve Şekil 9'da verilmiştir. Polimerin camsı geçiş sıcaklığı $118{ }^{\circ} \mathrm{C}$ olarak belirlenmiştir. Bu değer bir başka metakrilat polimeri olan metil metakrilat (108 ${ }^{\circ} \mathrm{C}$ ) ile karşılaştırıldığında (Crystal ve Frank 2000) daha yüksek bir değer olduğu görülmektedir. Bunun sebebinin kalkon ve hidroksil grubunun zincir haraketliliğini kısıtlaması ve serbest hacmi azaltması olarak düşünülmektedir. Serbest hacim azalırsa polimerin camsı geçiş sıcaklığı artmaktadır.

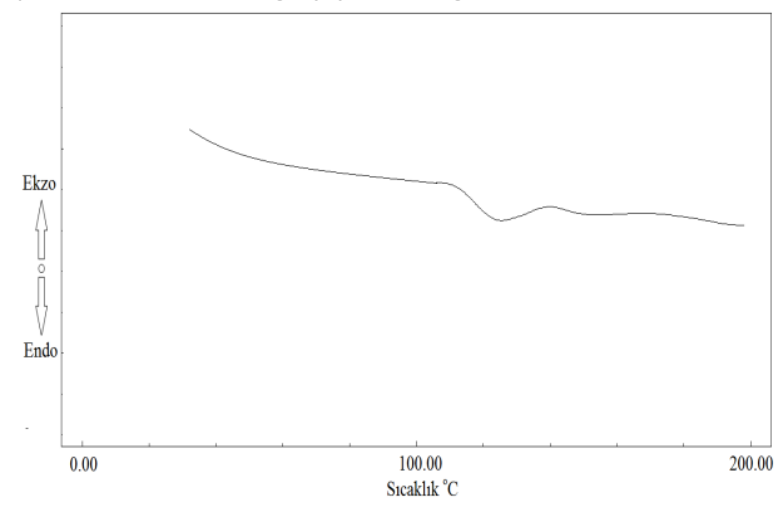

Şekil 8. $P(M K A L-M E T)^{\prime}$ ın DSC eğrisi.

$\mathrm{P}(\mathrm{MKAL}-\mathrm{MET}$ )'ın aktivasyon enerjisi hesabı için farklı ısıtma hızlarında oda sıcaklığından $600{ }^{\circ} C^{\prime}$ ye elde edilen termogramlar karşılaştırmalı olarak Şekil 9' da verilmiştir. Farklı ısıtma hızlarındaki bozunma eğrilerinden yararlanarak, Flynn-Wall-Ozawa metoduna göre polimerin bozunmasına yönelik aktivasyon enerjileri belirlendi. $\mathrm{Bu}$ amaçla 1/T değerlerine karşılık $\log \beta$ değerleri grafiğe geçirildi.

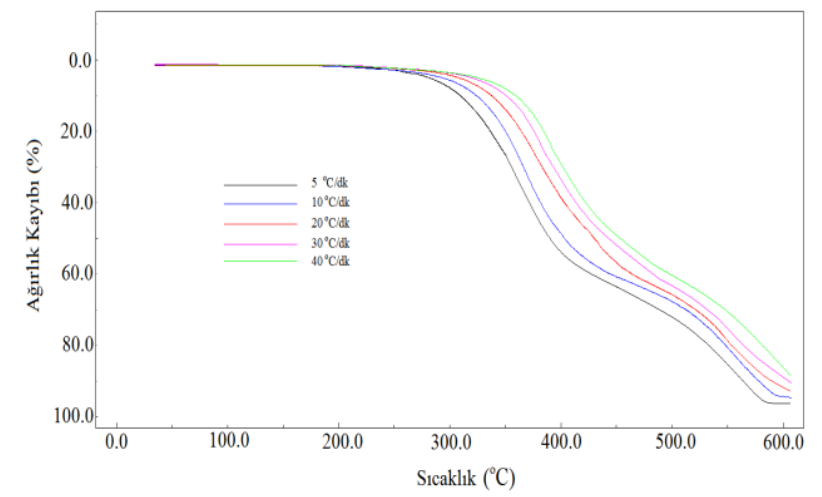

Şekil 9. P(MKAL-MET)'ın farklı ısıtma hızlarındaki TGA eğrileri

Flynn-Wall-Ozawa eğrileri olarak tanımlanan bu eğriler karşılaştırmalı olarak Şekil $10^{\prime}$ da gösterildi. Bu doğruların eğimleri belirlendikten sonra Eşitlik 1 kullanılarak her dönüşüm için aktivasyon enerjileri hesaplandı. Hesaplanan bu değerlerin dönüşüm yüzdelerine karşı değişimi Şekil 11'de gösterilmiştir. Eşitlikte $\beta$ ısıtma hızı ${ }^{\circ} \mathrm{C} / \mathrm{dk}$, Ea aktivasyon enerjisi, T sıcaklık ve $\mathrm{R}\left(8,314 \mathrm{~J} / \mathrm{mol}^{-1} \mathrm{~K}^{-1}\right)$. Ortalama aktivasyon değeri $141,26 \mathrm{~kJ} / \mathrm{mol}$ olarak bulundu ve bu değer literatürdeki metakrilat polimerlerine yakın değer olarak belirlendi (Biryan ve Demirelli 2017, Biryan ve ark 2017).

$\ln (\beta)=$ sabit $-1.052 \frac{E_{a}}{R . T}$

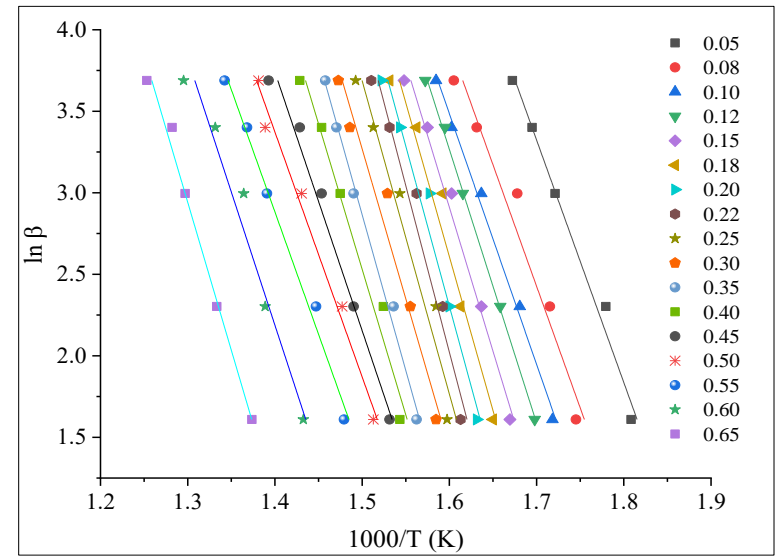

Şekil 10. P(MKAL-MET)'ın Flynn-Ozawa eğrileri. 


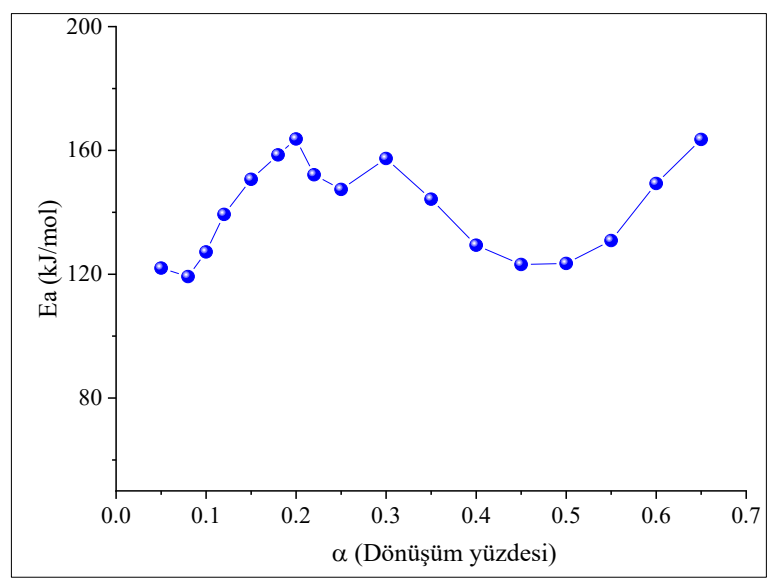

Şekil 11. $P(M K A L-M E T)^{\prime} ı n$ Ea değerlerinin dönüşümle değişimi.

Elde edilen $\mathrm{P}(\mathrm{MKAL}-\mathrm{MET})$ polimeri ve $\mathrm{EuCl}_{3}$ ile katkılanmış kompozitlerin dielektrik ve elektriksel özellikleri farklı sıcaklık değerlerinde 100 Hz- 30 kHz değişen frekans aralığında ölçüldü. Polimerin iyonik, elektronik ve moleküler polarlanabilirliğinin bir sonucu olarak dielektrik özellikler de değişim göstermektedir.

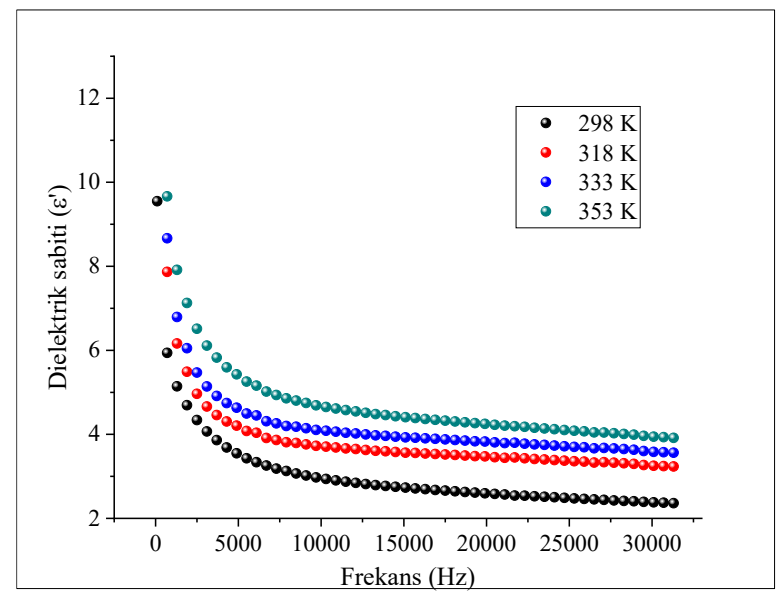

Şekil 12. P(MKAL-MET)'in farklı sıcaklıklarda frekansa karşı dielektrik sabitindeki değişimler.

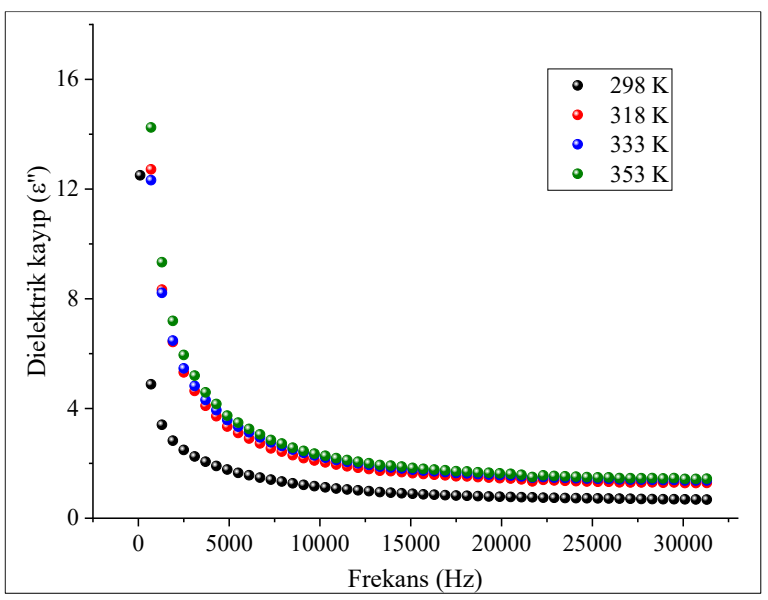

Şekil 13. P(MKAL-MET)'in farklı sıcaklıklarda frekansa karşı dielektrik kayıp'taki değişimler.
Polimerin artan frekans ile dielektrik özelliklerinde değişim gözlenmektedir (Şekil 12, 13 ve 14). Dielektrik sabitindeki değişim karşılaştırmalı olarak Şekil 12'de görülmektedir. Grafikte de görüldüğü üzere polimerin dielektrik sabiti artan frekans ile ilk olarak azalma göstermekte fakat yüksek frekanslarda sabit kalmaktadır. Bunun sebebi yüksek frekanslarda ara yüzey kutuplaşma mekanizması olmaz ve bu nedenle yüksek frekanslarda dielektrik sabiti düşüş göstermemektedir (Ramya ve ark. 2005).

Sıcaklık arttıkça molekülde düzensizlikler oluşur ve yük taşıyıcıların (iyonlar ve elektronlar) konsantrasyonu ve hareketliliği artar. Aynı zamanda iyon sıçraması ve yönelimi meydana gelir ve böylelikle dielektrik sonuçlarından da görüldüğü gibi sıcaklık arttıkça $\varepsilon, \varepsilon^{\prime \prime}$ ve $\sigma_{\mathrm{ac}}$ değerlerinde artış gözlenmektedir.

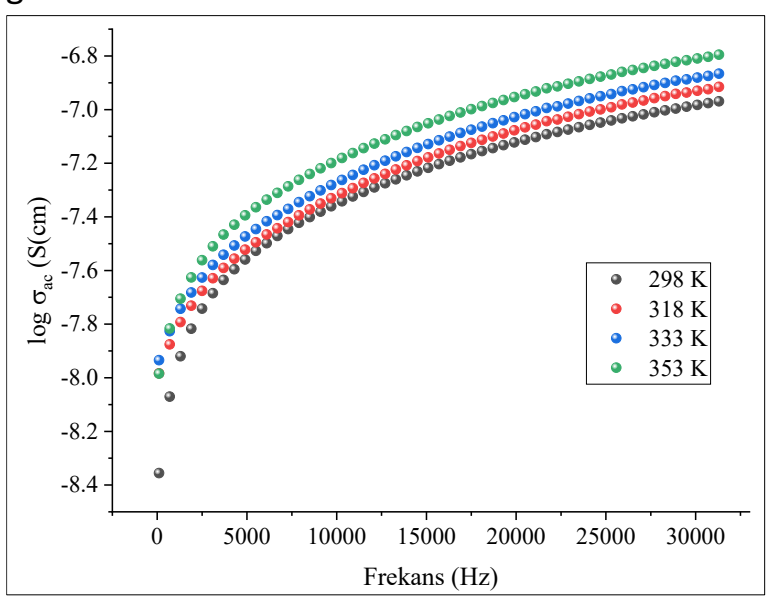

Şekil 14. P(MKAL-MET)'in farklı sıcaklıklarda frekansakarşı ac iletkenlik $\left(\log \sigma_{a c}\right)$ değerlerindeki değişimler.

Polimerin dielektrik sabitleri üzerine sıcaklığın etkisi incelendiğinde, yüksek sıcaklıklarda da arttığı görülmektedir (Afifi ve ark 2001, Biryan ve Demirelli 2018). Bunun sebebi sıcaklığın artmasıyla birlikte dipollerin haraketliliği ve polarizasyonunun artmasıdır. $298 \mathrm{~K}$ de dielektrik sabiti 5,34 iken aynı frekans değerinde $353 \mathrm{~K}$ de ise 8,39 olarak belirlenmiştir. Dielektrik sabitleri artan frekansla düşüş göstermiş, yüksek frekanslarda dielektrik sabitindeki bu düşme eğilimi azalmakta ancak düşüş halen devam etmektedir (Ramesh ve ark. 2002, Patel ve ark. 2013). Bu ani azalmalar düşük frekans bölgesinde numuneye etki eden elektriksel alan ile aynı yönde, moleküllerde yer alan yüklü dipollerin hareket etme eğilimlerinin yüksek olmasından kaynaklanmaktadır (González-Guisasola ve Ribes- 
Greus 2018, Sergejus ve ark. 2017). Polimerin artan sıcaklık ve frekansa karşı ac iletkenlik değerleri incelendiğinde (Şekil 14) sıcaklık ve frekansla arttığı gözlenmiştir. P(MKAL-MET) için $1 \mathrm{kHz}$ sabit frekansta $298 \mathrm{~K}$ 'de iletkenlik değeri $(\sigma) 1,08 \times 10^{-8}$ $\mathrm{S} / \mathrm{cm}$ iken sıcaklık $353 \mathrm{~K}$ e çıktığında $1,82 \times 10^{-8}$ $\mathrm{S} / \mathrm{cm}^{\prime}$ ye yükselmiştir. Aynı bileşik için sıcaklık sabit iken $100 \mathrm{~Hz}$ de $\sigma_{\mathrm{ac}}$ değeri $4,41 \times 10^{-9} \mathrm{~S} / \mathrm{cm}$ iken $30 \mathrm{kHz}$ de $1,04 \times 10^{-7} \mathrm{~S} / \mathrm{cm}$ olarak bulunmuştur. Bu sonuçlar incelendiğinde bileşiklerin iletkenliğinin hem frekansa hem de sıcaklığa duyarlı olduğu ve bu ölçütlerin artması ile arttığı görülmüştür. Bu tür malzemelerin faydası bu maddelerin elektriksel özelliklerine dayanır. Bu tür maddeler; elektriksel yalıtkan, dielektrik kapasitörü ya da mikrodalga aygıtlarının parçalarında kullanılabilme potansiyeline sahiptirler (Yuxing ve Davud 2008).

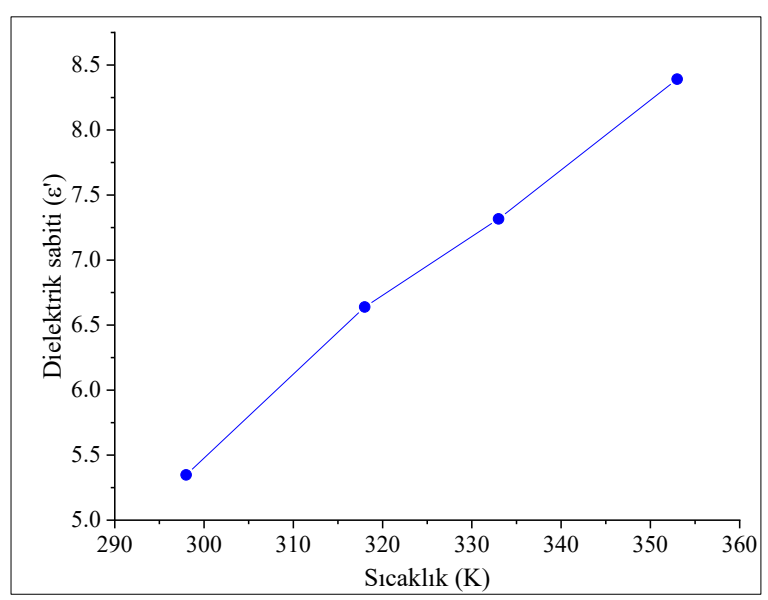

Şekil 15. $\mathrm{P}(\mathrm{MKAL}-\mathrm{MET})$ 'in $1 \mathrm{kHz}$ sabit frekansta dielektrik sabitinin sıcaklık ile değişim grafiği.

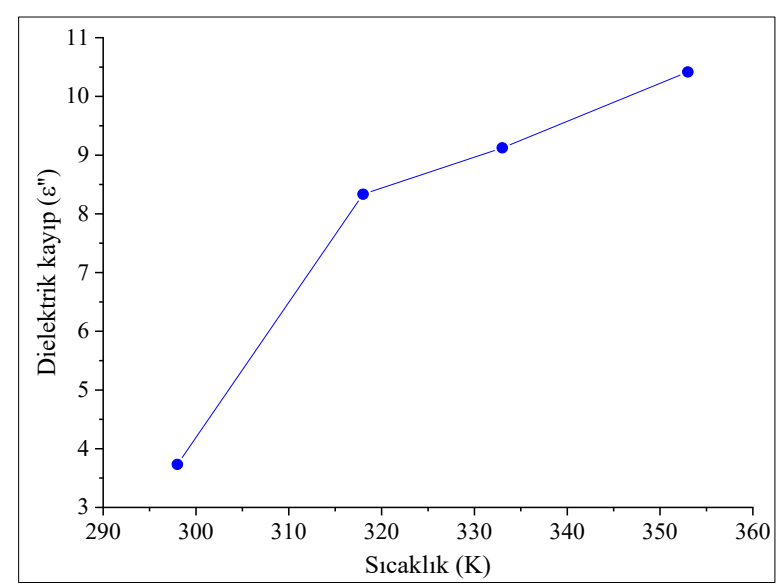

Şekil 16. $\mathbf{P}(\mathrm{MKAL}-\mathrm{MET})$ 'in $1 \mathrm{kHz}$ sabit frekansta dielektrik kayıp’ın sıcaklık ile değişim grafiği.

Polimerin artan sıcaklık ve frekansa karşı dielektrik kayıp faktörleri incelendiğinde sıcaklık ile artma, frekansla ise sürekli bir azalma eğilimi göstermiştir.

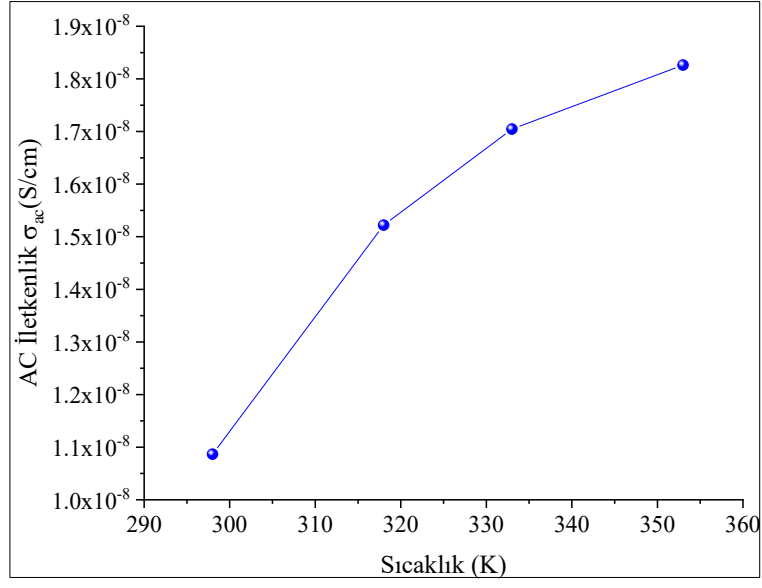

Şekil 17. P(MKAL-MET)'in $1 \mathrm{kHz}$ sabit frekansta ac iletkenliğin sıcaklık ile değişim grafiği.

Elde edilen sonuçlar bileşiklerin yapısı ile ilişkilendirildiğinde ve literatürdeki metakrilat polimerleri ile kıyaslandığında dielektrik sabitinin yüksek çıkması polimerin yapısında bulunan $-\mathrm{OH}$ ve kalkon grubunun moleküller arası polarizasyonun daha fazla olmasından kaynaklanmaktadır (Çelik ve Coşkun 2018, Biryan ve ark. 2017). 1kHz sabit frekans'ta dielektrik özelliklerin sıcaklıkla değişim grafikleri Şekil 15, 16 ve 17' de gösterilmiştir.

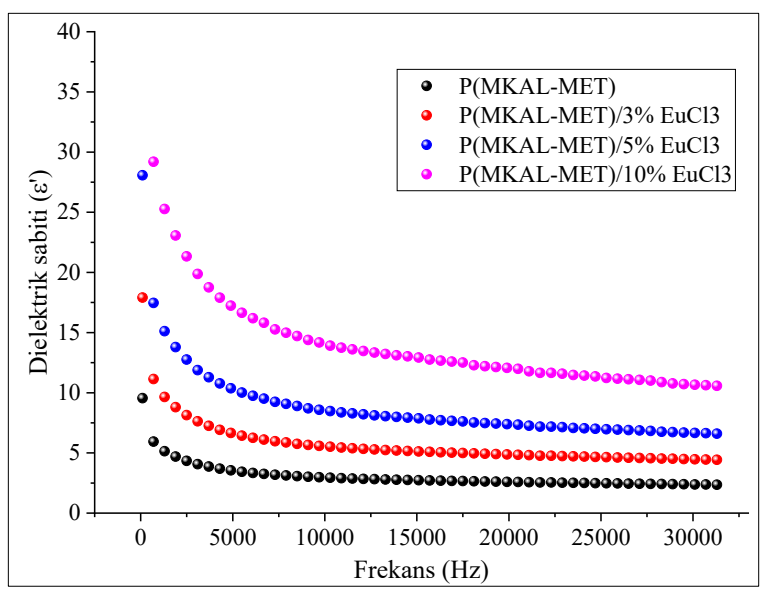

Şekil 18. P(MKAL-MET)/EuCl $\mathbf{B}_{3}$ kompozitlerinin farklı sıcaklıklarda dielektrik sabitinin frekans ile değişim grafiği. 


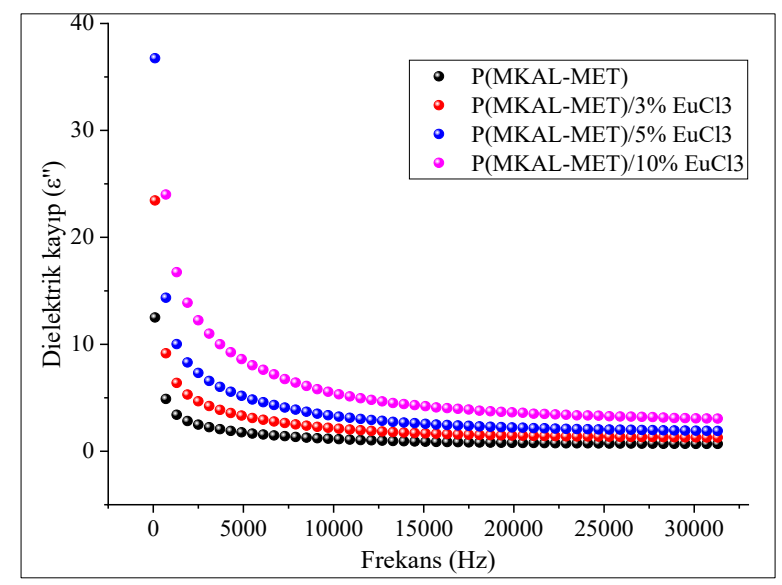

Şekil 19. $\mathrm{P}(\mathrm{MKAL}-\mathrm{MET}) / \mathrm{EuCl}_{\mathbf{3}}$ kompozitlerinin farklı sıcaklıklarda dielektrik kayıbın frekans ile değişim grafiği.

P(MKAL-MET) polimerine farklı oranlarda EuCl3 katkılanmış ve bu tuzun polimerin dielektrik özellikleri üzerine etkisi araştırılmıştır. Bu amaçla polimere ağırlıkça $\% 3, \% 5$ ve $\% 10$ oranında $\mathrm{EuCl} 3$ katkılanmış ve homopolimerin oda sıcaklığındaki özellikleri ile karşılaştırmak için $100 \mathrm{~Hz}-30 \mathrm{kHz}$ frekans aralığında dielektrik sabiti, dielektrik kayıp ve ac iletkenlik ölçümleri alınmıştır. Bu değerlerin karşılaştırmalı olarak Şekil $(18,19,20)^{\prime}$ de grafikleri çizilmiş ve değerleri Tablo 2'de özetlenmiştir.

Çizelge 2. P(MKAL-MET)/EuCl ${ }_{3}$ kompozitlerinin $25^{\circ} \mathrm{C}^{\prime} \mathrm{de}$ $1 \mathrm{kHz}$ 'deki Dielektrik Sonuçları.

\begin{tabular}{|c|c|c|c|c|}
\hline & $\% \mathrm{EuCl}_{3}$ & $\varepsilon^{\prime}$ & $\varepsilon^{\prime \prime}$ & $\sigma_{\mathrm{ac}}(\mathrm{S} / \mathrm{cm})$ \\
\hline P(MKAL-MET) & $\% 3$ & 10,03 & 7,00 & $2,03 \times 10^{-8}$ \\
\hline \multirow{2}{*}{$\begin{array}{c}\mathrm{X} \% \mathrm{EuCl}_{3} \\
\text { komp. }\end{array}$} & $\% 5$ & 15,72 & 10,97 & $3,19 \times 10^{-8}$ \\
\hline & $\% 10$ & 26,29 & 18,34 & $5,34 \times 10^{-8}$ \\
\hline
\end{tabular}

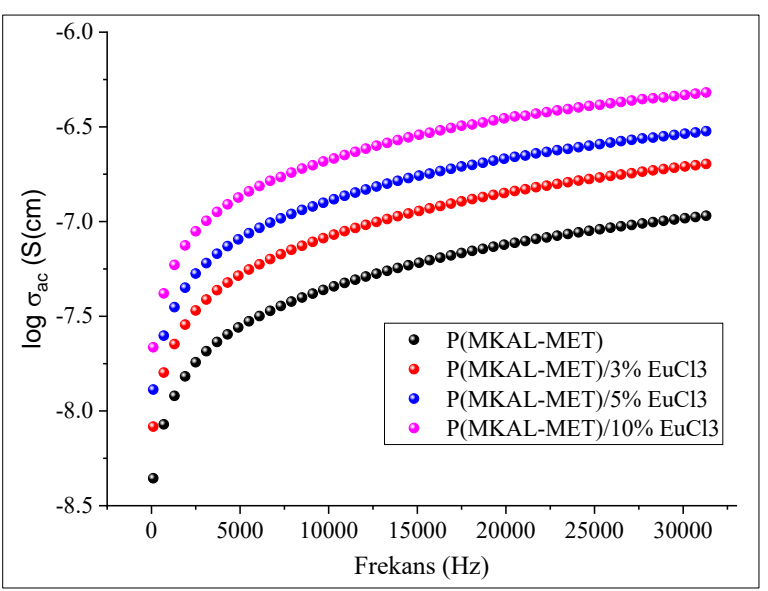

Şekil 20. P(MKAL-MET)/EuCl ${ }_{3}$ kompozitlerinin farklı sıcaklıklarda ac iletkenliğin frekans ile değişim grafiği.

Polimere $\mathrm{EuCl}_{3}$ katkılanmasıyla dielektrik sabitinde önemli artış gözlenmiştir. Dielektrik sabitindeki bu önemli artışın sebebi yüksek iyonik karakter ile birlikte yük taşıyıcılarının lokalizasyonunun artışından kaynaklanabilir. $1 \mathrm{kHz}$ de polimerlerin $\varepsilon^{\prime}$ ve $\varepsilon$ " değerlerinin sıcaklıkla değişimi incelendiğinde her iki değerin de artan sıcaklıkla artması, segmental hareketliliğin ve dipollerden kaynaklanan toplam polarizasyonunun yükselmesinden ileri gelmektedir (Sergejus ve ark. 2017, Abdel-Gawad ve ark. 2017). Grafiklerde de açıkça görülmektedir ki dielektrik sabiti frekansın artmasıyla azalmakta ve daha yüksek frekanslarda sabit bir değere ulaşmaktadır. Benzer davranışlar literatürde bazı polimerler için de kaydedilmiştir (Ayaz 2012). Sıcaklığın artmasıyla birlikte birçok iyon yük taşıyıcılar termal enerji ile yeterli aktivasyon enerjisine sahip olabilir. Aynı zamanda sıcaklık artışı zincir haraketliliğine ve polimerde serbest hacim artışına sebep olur ki buda polarizasyonu artırır (Biryan 2013).

\section{Tartışma ve Sonuç}

Bu çalışmada, yan grup olarak hidroksil ve kalkon içeren yeni homopolimerin dielektrik ve termal özelliklerinin belirlenmesi amaçlanmıştır. Sentezlenen bileşikler ve polimerin yapısal karakterizasyonları FT-IR, ${ }^{1} \mathrm{H}$ ve ${ }^{13} \mathrm{C}$-APT NMR spektroskopi yöntemleri ile doğrulandı. Termal davranışları ise DSC ve TGA termal analiz metotları ile belirlendi. Farklı ısıtma hızlarında TGA analizleri kullanılarak Flynn-Wall-Ozawa yöntemine göre aktivasyon enerjisi 141,26 kJ/mol olarak hesaplandı. Sentezlenen (MKAL-MET)'in dielektrik sabiti, dielektrik kayıp faktörü ve ac iletkenlik değerleri artan sıcaklığa karşı frekansın bir fonksiyonu olarak (100 Hz ile $30 \mathrm{kHz}$ arasında) empedans analizör cihazı ile belirlendi. Bu polimerin artan frekans ile dielektrik özellikleri değişmektedir. Dielektrik sabitinin frekans arttıkça azaldığı ve yüksek frekans değerlerinde sabit kaldığı, dielektrik kayıp faktörleri sıcaklıkla artıp, frekansla ise sürekli bir azalma eğilimi gösterdiği, ac iletkenlik değerlerinin ise sıcaklık ve frekansla arttığı gözlenmiştir. Bu davranış literatürde yapılan çalışmalarla kıyaslandığında sonuçların artan sıcaklık ve frekansla uyumluluk gösterdiği bulunmuştur (Koran ve ark. 2017, Biryan ve Demirelli 2017). Ayrıca farklı oranlarda $\mathrm{EuCl}_{3}$ ile katkılanarak dielektrik özelliklerdeki değişimler incelenmiştir. $\mathrm{EuCl}_{3}$ konsantrasyonundaki artışa paralel olarak dielektrik sabiti dielektrik kayıp ve ac 
ilektkenlik özelliklerinde önemli artış gözlemlenmiştir.

Çizelge 3. Hidroksil, kalkon yan grubu içeren bazı polimerlerin Termal ve dielektrik özelliklerinin karşılaştırması.

\begin{tabular}{|c|c|c|c|}
\hline $\begin{array}{l}\text { Literatürdeki } \\
\text { Benzer çalışmalar }\end{array}$ & IDTa & $\mathrm{Ea}(\mathrm{kJ} / \mathrm{mol})$ & $\varepsilon^{\prime}$ \\
\hline P(MKAL-MET) & 271 & 141,2 & 5,34 \\
\hline (Çelik ve Coşkun 2018) & 252 & 145,7 & 3,33 \\
\hline (Biryan ve Demirelli 2016) & 246 & 148,6 & 5,66 \\
\hline
\end{tabular}

Literatürde yapılan bir çalışmada kalkon grubu içeren metakrilat polimerinin oda sıcaklığında 1 kHz'deki dielektrik sabiti değeri 3,33 olarak belirlenmiştir (Çelik ve Coşkun 2018). Ayrıca hidroksil ve nitro benzen yan gruplu bir başka metakrilat polimerinin dielektrik sabiti 5,66 olarak rapor edilmiştir (Biryan ve Demirelli 2016). Bu çalışmadaki P(MKAL-MET)'ın dielektrik sabiti sadece kalkon grubu içeren polimere göre daha yüksek olarak belirlenmiştir. Bunun sebebi polimerin yapısında kalkon ve hidroksil grubunu birlikte ihtiva etmesinden dolayı elektrik alanda daha çok polarlanması olarak düşünülmektedir. Bu çalışmalara ait termal ve dielektrik özellikler Tablo 3'te özetlenmiştir. P(MKAL-MET) için 141,2 kJ/mol olarak bulunan ortalama aktivasyon enerji Tablo 3'te ki metakrilat polimerleri ile karşılaştırıldığında birbirine yakın olduğu görülmektedir.

Bu sonuçlar incelendiğinde polimerin iletkenliği hem frekansa hem de sıcaklığa duyarlı olup bu ölçütlerin artışıyla arttığı görülmüştür. Bu tür malzemelerin yararlılığı bu maddelerin elektriksel özelliklerine dayanır. Bu tür maddeler, elektriksel yalıtkan, dielektrik kapasitörü ya da mikrodalga aygıtlarının parçalarında kullanılabilme potansiyeline sahiptirler.

\section{Kaynaklar}

Abdel-Gawad, NMK, El Dein, AZ, Mansour, DEA, Ahmed, HM, FzDarwish, MM, Lehtonen, M, 2017. Multiple enhancement of PVC cable insulation using functionalized $\mathrm{SiO}_{2}$ nanoparticles based nanocomposites. Electric Power Systems Research, $163,612-625$.

Afifi, MA, Abd eł-wahabb E, Bekheet, AE, Atyia, HE, 2001. Effect of annealing on the ac conductivity and the dielectric properties of $\ln _{2} \mathrm{Te}_{3}$ thin films. Acta Physica Polonica A, 94, 4-9.

Ayaz, N, 2012. Benzilmetakrilat ile 2-Okso-2H-Kromen-7il Metakrilat kopolimerlerinin Sentezi ve Karakterizasyonu, Doktora Tezi, Fırat Üniversitesi Fen Bilimleri Enstitüsü, Elazığ, 143.

Bezgin, F, 2011. Kumarin İçerikli Polimerlerin Sentezi Spestroskopik ve Dielektrik Özellikleri, Doktora Tezi, Fırat Üniversitesi, Fen Bilimleri Enstitüsü, Elazığ, 162.

Biryan, F, 2013. Hidroksil Yan Gruplu Bazı Metakrilat Polimerlerin Sentezi, Termal Ve Dielektriksel Özelliklerin İncelenmesi, Yüksek Lisans Tezi, Fırat Üniversitesi, Fen Bilimleri Enstitüsü, Elazığ, 121.

Biryan, F, Demirelli, K, 2016. A methacrylate monomer bearing nitro, aryl, and hydroxyl side groups: Homopolymerization, characterization, dielectric, and thermal degradation behaviors. Journal of Applied Polymer Science, 37, 1-14.

Biryan, F, Demirelli, K, 2017. Characterization, thermal behavior, and electrical measurements of poly [4-(2bromoisobutyroylmethyl)styrene]. Advances in Polymer Technology, 37, 1994-2012.

Biryan, F, Demirelli, K, Torgut, G, PIhtılı, G, 2017. Synthesis, thermal degradation and dielectric properties of poly[2-hydroxy,3-(1-naphthyloxy) propylmethacrylate]. Polymer Bulletin, 74, 583-602.

Biryan, F, Demirelli, K, 2018. Temperature-frequency dependence on electrical properties of $\mathrm{EuCl}_{3}$ based composites, thermal behaviors and preparation of poly(3-acetamidopropyl acrylate). Ferroelectrics, 526, 76-94.

Coşkun, D, Coşkun, MF, 2017. Kalkon İçerikli Çapraz Bağlı Polimer Sentezi ve Asidik Hidrolizi. AKÜ FEMÜBID, 17(1), 66-72.

Coşkun, M, Temüz, MM, Koca, M, 2003. Thermal degadation behaviour of poly[(2-hydroxy-3phenoxy)propyl methacrylate] and poly[2-hydroxy-3tetrahydrofurfuryloxy)propyl methacrylate]. Polymer Degadation and Stability, 81, 95-102.

Crystal, EP, Frank, DB, 2000. Thermal Characterization of PMMA Thin Films Using Modulated Differential 
Scanning Calorimetry. Macromolecules, 33, 70167020.

Çelik, T, Coşkun, MF, 2018. Dielectric and thermal properties of the methacrylate polymer bearingchalcone side group. Journal of Molecular Structure, 1157, 239-246.

Funiss, BS, Hannford, AJ, Smith, PWG, Tatchell, AR, 2004. Vogel's Textbook of Practical Organic Chemistry. 5th ed., Longman, London, 1032-1035.

González-Guisasola, C, Ribes-Greus, A, 2018. Dielectric relaxations and conductivity of cross-linked PVA/SSA/GO composite membranes for fuel cells. Polymer Testing, 67, 55-67.

Koran, K, Tekin, Ç, Biryan, F, Tekin, S, Sandal, S, Görgülü, AO, 2017. Synthesis, structural and thermal characterizations, dielectric properties and in vitro cytotoxic activities of new 2,2,4,4-tetra(4'-oxysubstituted-chalcone)-6,6-diphenylcyclo triphosphazene derivatives. Medicinal Chemistry Research, 26, 962-974.

Maitz, MF, 2015. Applications of synthetic polymers in clinical medicine. Biosurface and Biotribology, 1, 161176.

Modzelewska, A, Pettit, C, Achanta, G, Davidson, NE, Huang, P, Khan, SR, 2006. Anticancer activities of novel chalcone and bis-chalcone derivatives. Bioorganic and Medicinal Chemistry, 14, 3491-3495.

Neamen, DA, 1997. Semiconductor physics and devices 2nd ed, Mc Graw-Hill, New York, 420-450, 517-523.

Podkoscıelna, B, Gawdzık, B, Bartnıckı, A, 2006. Use of a New Methacrylic Monomer, 4,40-Di(2-hydroxy-3methacryloyloxypropoxy) benzophenone, in the Synthesis of Porous Microspheres. Journal of Polymer Science: Part A: Polymer Chemistry, 44, 7014-7026.

Patel, PK, Rani J, Adhlakha N, Singh H, Yadav KL, 2013. Enhanced dielectric properties of doped barium titanate ceramics. Journal of Physics and Chemistry of Solids. 74, 545-549.

Perez, M, Ronda, JC, Reina, JA, Serra, A, 2000. Synthesis of functional polymers by modification of $\mathrm{PECH}$ and
PECH-PEO with substituted phenolates. Polymer, 42, 1-8.

Popescu, D, Hoogenboom, R, Keul, H, Moeller, M, 2010. Hydroxy functional acrylate and methacrylate monomers prepared via lipase-catalyzed transacylation reactions. Journal of Molecular Catalysis B: Enzymatic, 62, 81-90.

Ramesh, S, Yahana, AH, Aroof, AK, 2002. Dielectric behaviour of PVC-based polymer electrolytes SolidState. Ionics, 152-153, 291-294.

Ramya, CS, Savitha, T, Selvasekharapandian, S, Kumar G. $\mathrm{H} ., 2005$. Transport Mechanism of $\mathrm{Cu}$-ion Conducting PVA Based Solid-Polymer Electrolyte. Ionics. 11, 436441.

Sergejus, B, Maksim I, Jūras B, Satoshi, W, 2017. Dielectric Properties of $\mathrm{BaTiO}_{3}-\mathrm{KNbO}_{3}$ Composites. Ferroelectrics, 512, 8-13.

Symth, CP, 1955. Dielectric behaviour and structure. McGraw-Hill, New York, 52-61, 202-215.

Tareev, B, 1975. Physics of dielectric materials, Mir Publishers, Moscow.

Yuxing, R, Davud, CL, 2008. Properties and Microstructures of LowTemperature Processable Ultralow-Dielectric Porous Polyimide Films. Journal of Electronic Materials, 37, 21-28.

Zoglio, MA, Windheuser, JJ, Vatti, R. Maulding, HV, Kornblum, Jr SS, Jacobs, AL, et al., 1968. Linear Nonisothermal Stability Studies. Journal of Pharmaceutical Sciences, 57, 2080-2085. 